\title{
OPTIMASI KOMBINASI SUKROSA-MANITOL SEBAGAI PENGISI DALAM SEDIAAN TABLET HISAP EKSTRAK KENTAL BIJI PINANG (Areca catechu L.) SECARA GRANULASI BASAH
}

\author{
OPTIMIZING COMBINATION SUCROSE-MANNITOL AS \\ FILLER LOZENGES ARECA SEED EXTRACT (Areca catechu L.) \\ IN WET GRANULATION
}

\author{
Ari Widayanti, Rahmah Elfiyani, Ferra Tania \\ FFS Universitas Muhammadiyah Prof. DR. Hamka, \\ Jl. Islamic Center, Perumnas Klender, JakartaTimur. Telp.(021) 86603233. \\ Email:ariwidayanti@yahoo.com HP.0817 6813449
}

\begin{abstract}
ABSTRAK
Biji Pinang merupakan salah satu tanaman obat yang dapat dimanfaatkan untuk antiseptik karena kandungan dari salah satu biji pinang adalah tanin. Penelitian ini bertujuan untuk mengetahui optimasi kombinasi sukrosa-manitol dalam sediaan tablet hisap ekstrak kental biji pinang secara granulasi basah. Penelitian ini diawali dengan evaluasi ekstrak kental biji pinang 70\%, lalu ekstrak kental biji pinang dibuat dalam 5 formula dengan perbandingan pengisi sukrosa dan manitol yaitu FI (1:1), FII (1:2), FIII (1:3), FIV (1:4), FV (1:5). Pembuatan granul dibuat secara granulasi basah kemudian dilakukan evaluasi granul dan evaluasi tablet. Hasil uji kekerasan tablet diperoleh F1 12,50 kg/cm $;$ F2 11,71 kg/cm $;$ F3 11,01 $\mathrm{kg} / \mathrm{cm}^{2}$; F4 $10,70 \mathrm{~kg} / \mathrm{cm}^{2}$ dan F5 $10,27 \mathrm{~kg} / \mathrm{cm}^{2}$. Selanjutnya data kekerasan yang diperoleh dianalisa secara statistik ANOVA satu arah diperoleh nilai sig $(0.000)<$ $\alpha(0.05)$, maka terdapat perbedaan bermakna pada tiap formula yang kemudian dilanjutkan pada uji Tukey. Berdasarkan hasil statistik kombinasi pengisi sukrosamanitol F1, F3 dan F5 memiliki perbedaan sifat fisik yang bermakna pada kekerasan. Pada kelima formula yang memenuhi syarat secara keseluruhan yaitu F4 dan F5 dilakukan uji hedonis. Hasil analisa chi-square menunjukan bahwa F4 dan F5 tidak ada perbedaan yang bermakna pada uji kemanisan dan uji kesukaan aroma. Pada uji penampilan F4 ada perbedaan bermakna sedangkan F5 tidak ada perbedaan bermakna. Dapat disimpulkan F5 merupakan nilai optimal dan dapat diterima respon rasa di masyarakat.
\end{abstract}

Kata kunci: Areca catechul, sukrosa-manitol, tablet hisap 


\begin{abstract}
Areca seed (Areca catechu L.) is one of plant as a medicinal plant can used forantiseptic due to tannin as main content of Arecaseeds. This study aims at determining of combination optimization sucrose-mannitol in lozenges areca seed extract. This research begin with extract manufacture of Arecaseeds make by maceration using $70 \%$ ethanol as solution, viscous extract areca seeds lozenges make five formulas with ratio variation of sucrose-mannitol F1 (1:1), FII (2:1), FIII (3:1), FIV (4:1), FV (5:1). Granules were made by wet granulation. Then be evaluated for granule and evaluated of tablet. Results hardness test obtained F1 $12.50 \mathrm{~kg} / \mathrm{cm}^{2} ; F 211.71 \mathrm{~kg} / \mathrm{cm}^{2} ; F 311.01 \mathrm{~kg} / \mathrm{cm}^{2} ; F 410.70 \mathrm{~kg} / \mathrm{cm}^{2}$ and $F 510.27$ $\mathrm{kg} / \mathrm{cm}^{2}$. These result hardness were obtained statistically one-way ANOVA $(\alpha=$ $0.05)$ analyzed that hardness test got sig $0.000<0.05$. These results indicate a significant difference among all formulas. The Tukey indicated significant differences on F1, F3, and F5. The F4 and F5 followed by hedonic test. Results of chi-square analysis indicated F4 and F5, on sweetness test and preference scent test no different significant. On appearance test there was no significant difference F4 and there was difference significant F5, it can be concluded that F5 is optimum formula can acceptable sense respon in community.
\end{abstract}

Keyword: Areca catechu, sucrose-mannitol, lozenges

\section{PENDAHULUAN}

Masyarakat Indonesia telah mengenal tanaman-tanaman yang mempunyai khasiat untuk mengobati atau menyembuhkan berbagai macam penyakit sejak zaman dahulu. Salah satu tanaman yang digunakan sebagai tanaman obat adalah pinang. Secara tradisional, biji pinang dimanfaatkan oleh para orang tua dari generasi ke generasi sebagai salah satu bahan untuk makan sirih. Kebiasaan ini dipercaya dapat memperkuat gigi dan gusi.

Dalam bidang kesehatan mulut, masalah yang sering dihadapi adalah karies atau plak gigi, yang terdiri atas kumpulan bakteri yang berkembang biak dan melekat erat di permukaan gigi, yaitu bakteri Streptococcus mutans. Di dalam biji pinang terdapat tanin yang tidak hanya berefek untuk pengelat tapi juga digunakan untuk perlindungan karena mempunyai daya antiseptik ( Saad, 2007). Biji pinang juga mengandung beberapa alkaloid seperti arekolin, guavasin, guakolin, danarekain.

Masyarakat biasanya menggunakan air rebusan biji pinang dan menggunakannya sebagai obat kumur (Kasim, 2005). Namun cara ini kurang praktis digunakan sehingga perlu dibuat sediaan berupa tablet hisap. Tablet hisap mudah digunakan yaitu cukup 
dihisap dan tidak perlu menggunakan air untuk menelannya karena tablet langsung kontak dengan cairan saliva yang ada dalam mulut sehingga tablet akan pecah dengan sendirinya. Tablet hisap akan hancur secara perlahan dalam mulut sehingga kontak dengan rangsang rasa lebih lama, oleh karena itu pada formula tablet hisap tersebut bahan tambahan sedapat mungkin dipilih yang mampu menutupi rasa tidak enak dari bahan obatnya.

Pada penelitian ini menggunakan bahan tambahan sukrosa-manitol sebagai bahan pengisi sekaligus pemanis. Sukrosa merupakan bahan pengisi yang sering digunakan dalam pembuatan tablet hisap karena rasanya yang manis. Sukrosa mempunyai sifat alir yang baik tetapi waktu larutnya cepat karena mempunyai sifat higroskopis, oleh sebab itu perlu dikombinasikan dengan manitol. Yaitu bahan pemanis yang biasa digunakan dalam formulasi tablet hisap, memiliki sifat yang manis dan terasa dingin bila di mulut, kelarutannya lambat dan relative tidak higroskopis, tidak menyebabkan caries gigi serta dapat menutupi rasa pahit dari zat aktif pada formulasi tablet hisap (Ansel,1989). Proses pencetakan tablet hisap digunakan metode granulasi basah karena baik digunakan untuk bahan yang tahan terhadap suhu pemanasan.
Penelitian ini dilakukan untuk mengetahui optimasi konsentrasi bahan pengisi yang tepat sehingga akan diperoleh formula tablet hisap ekstrak biji pinang yang memiliki sifat fisik yang optimum dan respon rasa yang diterima oleh konsumen (Siregar, 2010).

\section{METODE PENELITIAN}

Bahan penelitian ekstrak kental biji pinang diperoleh dari Balai Penelitian Tanaman Obat dan Aromatik (BALITTRO), sukrosa, manitol, gelatin, nipagin, nipasol, talk, magnesium stearat, aquadest.

Alat penelitian berupa alat-alat gelas, lumpang, alu, oven, pemanas listrik, timbangan analitik, friabilator tester, hardness tester, mesin pencetak tablet, jangka sorong, stopwatch, granule flow tester, alat penguji waktu hancur (disintegration tester),tapped density tester, pengayak 12 dan 16, tanur, eksikator, $\mathrm{pH}$ meter dan viskometer brookfield.

Uji Karakteristik ekstrak kental biji pinang berupa pemeriksaan organoleptis yang dilakukan secara visual meliputi bentuk, warna, bau, dan rasa (DepKes RI, 1989).

Kekentalan: Dimasukkan ekstrak kental ke dalam beker glas $100 \mathrm{ml}$ kemudian dimasukkan spindel no.4 dalam sediaan hingga batas lalu dilakukan pengamatan pada kecepatan putaran $20 \mathrm{rpm}$ pada alat Viskometer Brookfield, kemudian 
dihitung kekentalan yang didapat dengan satuan Cps.

Uji sisa pemijaran: Ditimbang sejumlah 2 gram ekstrak kental biji pinang dan dimasukan ke dalam krus yang telah dipijarkan dan telah ditara. Ditambahkan $\mathrm{H}_{2} \mathrm{SO}_{4}$ pekat 2 tetes untuk mempercepat terjadinya arang. Kemudian dipijarkan dalam tanur hingga menjadi abu. Proses pengabuan dilakukan pada suhu $800^{\circ} \mathrm{C}$ selama 6 jam, kemudian didinginkan dalam eksikator dan ditimbang hingga bobot konstan.

Pemeriksaan $\mathrm{pH}$ : pengukuran menggunakan alat $\mathrm{pH}$ meter, kalibrasi alat terlebih dahulu dengan menggunakan larutan dapar $\mathrm{pH} 4$ dan $\mathrm{pH}$ 7. Ekstrak kental biji pinang dimasukkan ke dalam beker gelas, kemudian dimasukkan elektroda ke dalam sampel. Nilai $\mathrm{pH}$ yang diperoleh dicatat.

Perhitungan Randemen:

Sebanyak $15 \mathrm{~kg}$ biji pinang segar menghasilkan serbuk biji pinang sebanyak 1,5 Kg. Ekstrak kental yang diperoleh 306,5 gram.

Randemen terhadap biji pinang segar

$=\frac{\text { ekstrak kental biji pinang }}{\text { berat serbuk biji pinang }} \times 100 \%$

$=\frac{306,5 \mathrm{~g}}{1500 \mathrm{~g}} \times 100 \%$

$=20,43 \%$

Perhitungan Dosis

Pada penelitian sebelumnya ekstrak biji pinang sebagai antibakteri Streptococcus mutans dari $100 \mathrm{~g}$ serbuk simplisia dimaserasi dengan etanol $70 \%$ diperoleh 26,54 gram ekstrak kental biji pinang dan berkhasiat sebagai antibakteri pada konsentrasi $2,5 \%$.

Perhitungan untuk ekstrak kental biji pinang yang digunakan pada tiap tablet adalah

$$
=\frac{20,43 \%}{26,54 \%} \times 2,5 \%=1,92 \%
$$

Jadi dosis untuk tablet hisap biji pinang $700 \mathrm{mg}$ adalah:

$$
=\frac{1,92}{100} \times 700 \mathrm{mg}=13,44 \mathrm{mg}
$$

Formula Tablet

Tablet dibuat dalam lima formula yakni formula F1, F2, F3, F4 dan F5. Kelima formula tersebut dibedakan konsentrasi bahan pengisinya dengan bobot setiap tablet $700 \mathrm{mg}$ seperti tersaji pada Tabel I. (Wade, 2009).

Pembuatan tablet hisap ekstrak kental biji pinang:

Larutan gelatin dibuat dengan membiarkan gelatin terhidrasi dalam air dingin untuk beberapa jam atau semalaman, kemudian campuran dipanaskan sampai mendidih. Larutan gelatin harus digunakan saat masih panas karena larutan ini akan membentuk gel pada suhu di bawah $40^{\circ} \mathrm{C}$. Dalam lumpang hangat ekstrak biji pinang dimasukkan dan ditambah dengan sukrosa dan manitol, lalu digerus hingga homogen. Ditambahkan nipaginnipasol yang telah dilarutkan dengan 
Tabel I. Formula Tablet Hisap Biji Pinang

\begin{tabular}{lcccccc}
\hline \multicolumn{1}{c}{ Bahan } & F I & F II & F III & F IV & F V & Fungsi \\
\hline $\begin{array}{l}\text { Ekstrak kental } \\
\text { biji pinang( \%) }\end{array}$ & 1,92 & 1,92 & 1,92 & 1,92 & 1,92 & Zat aktif \\
$\begin{array}{l}\text { Gelatin (\%) } \\
\text { Nipagin (\%) }\end{array}$ & 2,5 & 2,5 & 2,5 & 2,5 & 2,5 & Pengikat \\
Nipasol (\%) & 0,1 & 0,1 & 0,1 & 0,1 & 0,1 & Pengawet \\
Talk (\%) & 0,01 & 0,01 & 0,01 & 0,01 & 0,01 & Pengawet \\
Mg. Stearat (\%) & 2 & 2 & & 2 & 2 & Pelicin \\
$\begin{array}{l}\text { Sukrosa manitol } \\
\text { (perbandingan) }\end{array}$ & $1: 1$ & 2 & 2 & 2 & 2 & Pelincir \\
\hline
\end{tabular}

etanol, dicampur dan digerus kembali hingga homogen dan ditambahkan mucilago gelatin sampai terbentuk massa yang dapat dikepal (banana breaking) kemudian diayak dengan ayakan No.12. Granul yang terbentuk dikeringkan dalam lemari pengering bersuhu $50^{\circ} \mathrm{C}$ selama 24 jam.

Granul yang telah kering diayak dengan ayakan No.16. Kemudian ditambahkan Mg. Stearat dan talk, diaduk hingga homogen. Lalu dilakukan evaluasi granul dan massa tablet selanjutnya dicetak dengan mesin pencetak tablet, kemudian dilakukan evaluasi tablet (Voigt,1994).

Evaluasi sifat fisik granul

Evaluasi fisik granul yang dilakukan meliputi : waktu alir, sudut diam, kompresibilitas, distribusi ukuran granul, susut pengeringan granul (Lachman, 1994).

Evaluasi Tablet hisap

Evaluasi tablet meliputi: organoleptis, keseragaman ukuran, keseragaman bobot, (DepKes RI 1979) kekerasan tablet, keregasan, dan uji waktu hancur ( DepKes RI,1995). Selain itu juga dilakukan uji kesukaan. Uji kesukaan (hedonist test): Dua puluh orang panelis laki laki dan perempuan diminta untuk melihat penampilan fisik, mencium aroma, dan menghisap tablet dan melakukan penilaian untuk mengetahui tingkat kesukaan terhadap rasa dan kesukaan dari masing-masing tablet hisap dengan cara mengikuti instruksi yang tercantum pada kuisioner.

\section{HASIL DAN PEMBAHASAN}

Hasil karakteristik ekstrak kental biji pinang: Bentuk kental agak lengket, bau khas aromatik, Rasa pahit agak kelat, warna merah bata kecoklatan seperti tersaji pada Tabel II. Hasil organoleptik tablet hisap ekstrak kental biji pinang: bau khas aromatik, warna merah muda, permukaan licin, bentuk tabung.

Hasil evaluasi massa granul: Berdasarkan hasil evaluasi yang telah 
dilakukan, granul formula 1 sampai formula 5 secara keseluruhan memenuhi persyaratan, seperti tersaji pada table III. Kemudian dilakukan pencetakan tablet hisap pada penampilan tablet semua formula yang dihasilkan tidak berbeda yaitu mempunyai bentuk bulat tabung, berwarna merah muda, berbau khas biji pinang, permukaan rata dan halus, serta mengkilap. Pada pengujian diameter tablet mempunyai diameter yang sama yaitu $13,80 \mathrm{~mm}$ dan tebal tablet bervariasi, hal ini dipengaruhi oleh jumlah granul yang dapat diisi ke dalam cetakan pada saat pengempaan.

Hasil Evaluasi Tablet Ekstrak Kental Biji Pinang tersaji pada table IV.
Pengujian keseragaman bobot diperoleh hasil bahwa semua formula tidak ada yang menyimpang dari persyaratan Farmakope Indonesia III. Bahwa bobot tablet hisap memenuhi persyaratan yaitu tidak boleh lebih dari 2 tablet yang masing-masing bobotnya menyimpang dari bobot rata-ratanya lebih besar dari kolom $\mathrm{A}$ dengan bobot penyimpangan ratarata 5\% dan tidak satu talet pun yang bobotnya menyimpang dari bobot rata-ratanya lebih dari kolom $B$ dengan bobot penyimpangan ratarata $10 \%$.

Pada pengujian kekeras an semua formula memenuhi persyaratan karena persyaratan kekerasan tablet hisap yang baik adalah $10-20 \mathrm{~kg}$.

Tabel II. Hasil karakteristik ekstrak

\begin{tabular}{ll}
\hline Pengujian & Hasil \\
\hline Susut pengeringan (\%) & 5,82 \\
Sisa pemijaran (\%) & 1,04 \\
Uji viskositas (Cps) & 9796 \\
Uji pH & 4,56 \\
\hline
\end{tabular}

Tabel III. Hasil evaluasi granul

\begin{tabular}{lccccc}
\hline \multirow{2}{*}{ Formula } & \multicolumn{5}{c}{ Evaluasi } \\
\cline { 2 - 6 } & $\begin{array}{c}\text { Waktu alir } \\
(\text { detik })\end{array}$ & $\begin{array}{c}\text { Sudut } \\
\text { diam }\left({ }^{\circ}\right)\end{array}$ & $\begin{array}{c}\text { Kompresibilitas } \\
(\%)\end{array}$ & $\begin{array}{c}\text { Ukuran } \\
\text { partikel }(\mu \mathrm{m})\end{array}$ & $\begin{array}{c}\text { Kadar } \\
\text { air }(\%)\end{array}$ \\
\hline F1 & 9,4 & 27,67 & 0,12 & 1048,08 & 0,75 \\
F2 & 9,5 & 27,75 & 0,37 & 1055,30 & 0,80 \\
F3 & 9,7 & 28,13 & 0,54 & 1004,88 & 0,87 \\
F4 & 9,8 & 28,93 & 0,75 & 1015,69 & 0,90 \\
F5 & 9,9 & 29,36 & 0,95 & 1053,20 & 0,98 \\
\hline
\end{tabular}


Tabel IV. Evaluasi tablet hisap biji pinang

\begin{tabular}{ccccccc}
\hline & & \multicolumn{2}{c}{ Evaluasi tablet hisap esktrak biji pinang } \\
\cline { 2 - 7 } Formula & $\begin{array}{c}\text { Diameter } \\
(\mathrm{mm})\end{array}$ & $\begin{array}{c}\text { Ketebalan } \\
(\mathrm{mm})\end{array}$ & $\begin{array}{c}\text { Keseragaman } \\
\text { bobot }(\%)\end{array}$ & $\begin{array}{c}\text { Kekerasan } \\
\left(\mathrm{kg} / \mathrm{cm}^{2}\right)\end{array}$ & $\begin{array}{c}\text { Keregasan } \\
(\%)\end{array}$ & $\begin{array}{c}\text { Waktu hancur } \\
(\text { menit })\end{array}$ \\
\hline F1 & 13,80 & 4,30 & 705,22 & 12,50 & 0,12 & 15,47 \\
F2 & 13,80 & 4,33 & 712,94 & 11,70 & 0,37 & 13,46 \\
F3 & 13,80 & 4,25 & 707,62 & 11,01 & 0,54 & 11,06 \\
F4 & 13,80 & 4,27 & 708,70 & 10,70 & 0,75 & 8,20 \\
F5 & 13,80 & 4,35 & 710,09 & 10,27 & 0,95 & 6,97 \\
\hline
\end{tabular}

Pengujian keregasan tablet pada F1-F5, menyatakan bahwa semakin tinggi jumlah manitol akan meningkatkan keregasan. Hal ini disebabkan karena kompresibilitas manitol yang kurang baik. Nilai kerapuhan yang masih dapat diterima tidak boleh lebih dari 1\%. Pada pengujian waktu hancur F1, F2 dan F3 menyatakan bahwa tidak memenuhi persyaratan, sedangkan F4 dan F5 memenuhi persyaratan waktu hancur tablet hisap, yaitu 5-10 menit hancur perlahan dalam mulut (DepKes, 1995).
Pada pengujian waktu hancur menyatakan bahwa semakin banyak jumlah manitol, maka semakin cepat waktu hancur tablet hisap dalam mulut. Pada kelima formula yang memenuhi syarat secara keseluruhan adalah F4 dan F5 dilihat dari evaluasi granul dan evaluasi tablet hisap. Hasil Uji kesukaan (hedonis)

Pada uji hedonis meyatakan bahwa F4 mempunyai penampilan yang lebih menarik dari F5. Namun F5 memiliki rasa yang lebih manis dan aroma yang lebih disıkai oleh panelis, seperti tersaji pada table $\mathrm{V}$ dan gambar 1.

Tabel V. Hasil uji hedonis tablet hisap

\begin{tabular}{lll}
\hline Pengujian & Formula IV & Formula V \\
\hline Warna & Menarik & Netral \\
Rasa & Cukup manis & Manis \\
Bau & Cukup suka & Suka \\
\hline
\end{tabular}

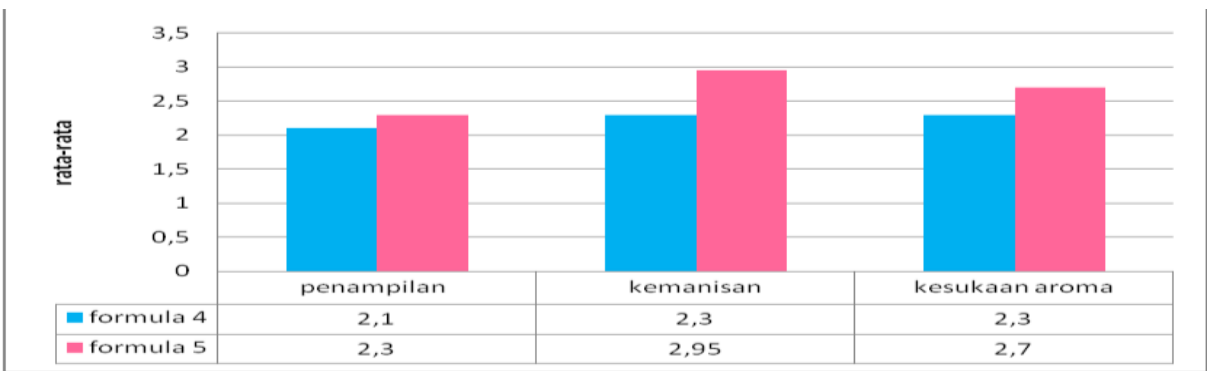

Grafik 1. Uji Hedonis tablet hisap 


\section{KESIMPULAN}

Dari penelitian ini dapat disimpulkan bahwa dari kelima formula yaitu pada Formula 1 (1:1), Formula 2 (1:2), Formula 3 (1:3), Formula 4 (1:4), Formula 5 (1:5), maka didapat satu formula yang optimum yaitu formula 5 dengan perbandingan sukrosa dan manitol 1:5 sebagai bahan pengisi pada tablet hisap ekstrak biji pinang (Areca catechu L.) dengan metode granulasi basah.

\section{DAFTAR PUSTAKA}

Saad, AA, 2007, Daya AntibakteriEkstrak Etanol Biji Pinang (Areca catechu) Terhadap Streptococcus mutans ATCC 25175 In Vitro, Skripsi, Fakultas Kedokteran Universitas Islam Indonesia, Yogyakarta. Hlm: 25

Kasim. E.,T. Yulinery, dan N. Nurhidayat, 2005, Pemanfaatan Se dari ekstrak biji dan akar pinang (Areca catechu L) yang difermentasi

Konsorsium Acetobacter-Saccharomyces sebagai Antiseptik Obat Kumur, Laporan Penelitian, LIPI, Bogor.

Departemen Kesehatan RI, 1989, Materia Medika Indonesia, Jilid V, Departemen Kesehatan RI, Jakarta, Hlm: 55

Departemen Kesehatan RI, 1995, Farmakope Indonesia, Edisi IV, Departemen Kesehatan RI, Jakarta, Hlm: 5, 1037-1038, 1043, 1086, 7, 404, 12, 762.

Voigt, R, 1994, Buku Pelajaran Teknologi Farmasi., Edisi V,
Terjemahan Soendani Noerono, UGM Press, Yogyakarta, Hlm: 166, 167, 206, 159, 159-162, 165-244.

Siregar, C., 2010, Teknologi Farmasi Sediaan Tablet Dasardasar Praktis, Buku Kedokteran EGC, Jakarta, Hlm: 1, 193, 198, 199, 223-224, 516, 521, 417, 506, 505-508, 512, 176, 235-237.

Ansel, H.C., 1989, Pengantar Bentuk Sediaan Farmasi, Edisi IV, Terjemahan F. Ibrahim, UI Press, Jakarta, Hlm: 244-245, 261, 266, 256, 257-258.

Lachman, L., Lieberman, H.A., and Kanig J.L., 1994, Teori dan Praktek Farmasi Industri, Jilid II, Edisi Ketiga, Terjemahan Suyatmi, UI Press, Jakarta, Hlm: 645, 697-698, 701, 703, 685, 682-683, 648-649, 651, 654.

Wadke, Deodatt A, Abu T.M Serajuddin and Harold Jacobs, 1969, Preformulation Testing, dalam Lachman, L. Lieberman H.A and Schwatz. JB. Pharmaceutical Dosage Form, Tablet, Volume 2, second edition revised and Expanded Marcel Dekker Inc, NewYork. Hlm: 5455

Lachman, L, Lieberman, H.A dan Kanig JL, 1997, The Theory an Practice of Industrial Pharmacy Second Edition, Lea and Febiger, Philadelpia. Hlm: 22-24, 102104.

Departemen Kesehatan RI, 1979, Farmakope Indonesia, Edisi III.Departemen Kesehatan RI, Jakarta Hlm: 6,7, 8, 9,

Wade, A., and Weller, P.J., 2009, Handbook of Pharmaceutical Exipients, Sixth edition, 
American Pharmaceutical Assosiation and Pharmaceutical Washington. The Pharmaceutical Press, London. Hlm : 704, 278-281, 728, 767.

Santoso, P.B. dan Ashari, 2005, Analisis Statistik dengan Microsoft excel dan SPSS, Penerbit Andi, Yogyakarta, Hlm: 67-68. 